\title{
ADMET Prediction and In silico Analysis of Mangostin Derivatives and Sinensetin on Maltase-Glucoamylase Target for Searching Anti-Diabetes Drug Candidates
}

\author{
Intan Kris Prasetyanti ${ }^{1}$, Sukardiman ${ }^{2, *}$, Suharjono ${ }^{3}$
}

Intan Kris Prasetyanti'

Sukardiman ${ }^{2, *}$, Suharjono ${ }^{3}$

1Magister Program of Pharmaceutical Sciences, Faculty of Pharmacist, Airlangga University, Campus C UNAIR J. DR. Ir. H Soekarno Mulyorejo 60115, Surabaya, INDONESIA.

${ }^{2}$ Department of Pharmaceutical Sciences, Faculty of Pharmacist, Airlangga University, Campus C UNAIR JI. DR. Ir. H Soekarno Mulyorejo 60115, Surabaya, INDONESIA.

${ }^{3}$ Department of Practical Pharmacy, Faculty of Pharmacist, Airlangga University, Campus C UNAIR JI. DR. Ir. H Soekarno Mulyorejo 60115, Surabaya, INDONESIA.

\section{Correspondence}

\section{Sukardiman}

Departement of Pharmaceutical Sciences, Faculty of Pharmacist, Airlangga University Campus C UNAIR JI. DR. Ir. H Soekarno Mulyorejo 60115, Surabaya, INDONESIA.

Phone no. +62 81330458449

E-mail: sukardiman@ff.unair.ac.id

History

- Submission Date: 29-03-2021;

- Review completed: 22-04-2021;

- Accepted Date: 12-05-2021.

DOI : 10.5530/pj.2021.13.113

Article Available online http://www.phcogj.com/v13/i4

Copyright

(C) 2021 Phcogj.Com. This is an open access article distributed under the terms of the Creative Commons Attribution 4.0 International license.

\begin{abstract}
Background: Diabetes mellitus (DM) is a complex chronic disease with hyperglycemia, which is glucose levels above normal whose number of sufferers is increasing. By inhibiting the human maltase-glucoamylase enzyme which is included in the starch-digestion pathway are used to delay glucose production and thus aid in the treatment of type II diabetes. Aims and Methods: To analyze the potential of mangostin derivatives (alpha-mangostin, betamangostin, gamma-mangostin) and sinensetin as anti-diabetes through ADMET prediction and in silico tests against human maltase-glucoamylase targets using the docking method with miglitol was used as a control. Result: The ligands a, $\beta, \gamma$-mangostin and sinensetin have good interactions with macromolecules and form hydrogen bonds also van der Waals on the macromolecule active side of human maltase-glucoamylase. Conclusion: The ADMET of mangostin derivatives ( $a, \beta$, and $\gamma$ ), and sinensetin can be predicted by the pkCSM online tool, and they showed good affinity on maltase-glucoamylase target compared to standard drugs like miglitol.
\end{abstract}

Key words: Mangostin derivatives, Sinensetin, Molecular docking, Maltase-glucoamylase, Anti-diabetes.

\section{INTRODUCTION}

Diabetes mellitus (DM) is a complex chronic disease with hyperglycemia, which is glucose levels above normal whose number of sufferers is increasing. It is characterized by a deficiency of insulin or reduced sensitivity to insulin followed by an increase in blood glucose and a disturbance in the metabolism of carbohydrates, protein, and lipid. ${ }^{1-3}$

Human Maltase-glucoamylase (MGA) is one type of alpha-glucosidase digestive enzyme in the human small intestine that works along with alpha-amylase and sucrose-isomaltase to digest carbohydrate and break it into glucose. ${ }^{4-10}$ Thus enzyme that works together with sucrose-isomaltase to catalyze the final stages of starch digestion through hydrolyzing mixtures of dextrins at the non-reducting end into glucose with net retention of anomeric configuration. By inhibiting this enzyme, it is hoped that the starch digestive pathway can delay the production of glucose in type-II diabetes. ${ }^{1}$

The potency of a-mangostin as an anti-diabetic was proven by administering a-mangostin isolated from pericarpium mangosteen extract to rats induced by streptozotocin (STZ). ${ }^{4} \gamma$-mangostin was also shown the results can reduce blood glucose in STZ-induced mice. ${ }^{2}$ Whereas $\beta$-mangostin is a mangostin derivative which is suspected to also have the potential to lower blood glucose. Potency sinensetin as anti-diabetes was proven isolate showed inhibition of a-glucosidase and a-amylase enzyme activity. Inhibition of these two enzymes is a control process for glucose absorption in type 2 diabetes mellitus. ${ }^{6}$

Molecular docking is a computational method that can provide information about intermolecular interactions of proteins, nucleic acids, lipids, and ligands. The purpose of molecular docking is to obtain optimized conformation of proteins and ligands also obtain a relative orientation between proteins and ligands through the minimized energy-free system.? In this paper, the potential of some Indonesian herbal compounds i.e mangostin derivatives ( $a, \beta$, $\gamma$-mangostin) and sinensetin were explored through a molecular docking method on MGA target. The docking performance of those herbal compounds will be compared with the docking performance of Miglitol as a standard ligand to define their potential as anti-diabetes drug candidates.

\section{MATERIALS AND METHODS}

\section{Hardware}

A Server computer with specifications: processor Intel(R) Celeron(R) CPU 847@1.10GHz, system type 64-bit Operating System, RAM 4.00 GB with Windows 8

\section{Software}

The software used is ChemDraw 20.0, Chem3D 20.0, AutoDockTools 1.5.6 (The Scripps Research Institute, USA), ProteinPlus online tool (https://proteins. plus/), Protein Data Bank online tool (https://www. rcsb.org), pkCSM online tool (http://biosig.unimelb. edu.au/pkcsm/prediction) and BIOVIA Discover Studio 2020

Cite this article: Prasetyanti IK, Sukardiman, Suharjono. ADMET Prediction and In silico Analysis of Mangostin Derivatives and Sinensetin on Maltase-Glucoamylase Target for Searching Anti-Diabetes Drug Candidates. Pharmacog J. 2021;13(4): 883-889. 


\section{D Structure}

The mangostin derivatives (a, $\beta, \gamma$-mangostin), sinensetin, positive controls (miglitol), macromolecules Human Maltase-glucoamylase.

\section{Preparation of macromolecule structure}

Preparation by searching and downloading macromelecules from the Protein Data Bank, optimization, and separation of non-standard residues. In this study, the macromolecule used is maltase-glucoamylase (PDB:3CTT).

\section{Preparation of ligand 3D structure}

The ligands used in the 2D structure (Figure 1) were copied as SMILES with the ChemDraw 20.0 program. Then it is converted into a $3 \mathrm{D}$ model using the Chem3D 20.0 program. Optimization and optimization by adding hydrogen, fixing charges, and minimization.

\section{Molecular docking of positive controls, mangostin derivatives ( $a$, $\beta, \gamma$-mangostin), and sinensetin}

The positive controls used were miglitol which activities had been recognized by the FDA for antidiabetes treatment. Molecular docking was performed using AutoDock4. The coordinates of the binding site were $\mathrm{x}=1,07 ; \mathrm{y}=-16,151 ; \mathrm{z}=20,571$ using $40 \mathrm{x} 40 \mathrm{x} 40$ unit grid box (macromolecule of maltase-glucoamylase). The result of molecular docking is saved as ${ }^{*}$.dlg file format.

\section{ADMET prediction of mangostin derivatives ( $a, \beta, \gamma$-mangostin) and sinensetin}

To determine the ADMET (Absorption, Distribution, Metabolism, Excretion, and Toxicity) of the compounds mangostin derivatives (a, $\beta$, $\gamma$-mangostin), and sinensetin was performed using the pkCSM online tool program by entering the SMILES form of the compound.

\section{RESULT AND DISCUSSION}

\section{Macromolecule}

Research using a molecular docking simulation approach using a computer with certain programs can carry out drug discovery studies, where it can reduce the cost and time required for drug discovery in general, as is known in the process of drug discovery requires a large cost and a long time (Geldenhuys et al, 2006). Compounds that have antidiabetic activity are mangostin derivatives ( $\alpha, \beta, \gamma$-mangostin) and sinensetin which show a decrease in blood glucose in streptozotocin (STZ)-induced experimental animals (Lee et al., 2018; Husen et al; Mohamed et al., 2012).

MGA macromolecules (Figure 2) are prepared by removing other unused receptor parts such as receptor chains other than those used for ligand docking, removing all existing cocrystal ligands so as not to interfere with the molecular docking process, removing water molecules, adding polar hydrogen, fix the lost atoms and additional charge. These steps need to be prepared to ensure that the molecular tethering of the macromolecules can produce good affinity and form stable interactions. The results of the identification of the active site of the macromolecule were carried out on the ProteinPlus online tool by entering the macromolecule format .pdb and the best results were obtained with the highest drug score of 0.73 and RMSD $0.708 \AA$ the pocket molecule was valid because the deviation obtained was less than $2 \AA .{ }^{5}$

The next docking process is to prepare ligands that will be used for the docking process, namely mangostin-derived ligands ( $\alpha, \beta, \gamma$-mangostin) and sinensetin ligands. In this study, miglitol is used for ligand positive control.

The protein-ligands interaction was analyzed and visualized using BIOVIA to inspect the hydrogen bond distance and van der Waals binding site (Figure 3). The result of the ligand-macromolecular interaction shows the affinity of the binding energy and inhibition constant values. The higher the affinity of the ligands is obtained when the binding energy value is less than zero and the inhibition constant value is low. ${ }^{8}$ The mangostin derivative that has the highest affinity is a-mangostin, this can be seen from the binding energy value of -7.84 $\mathrm{kcal} / \mathrm{mol}$ and the inhibition constant $1.78 \mu \mathrm{M}$ which is lower than the other mangostin derivatives ( $\beta$ and $\gamma$-mangostin. Sinensetin also showed high affinity, namely the binding energy value of $-7.45 \mathrm{kcal} /$ mol and a constant inhibition of $3.46 \mu \mathrm{M}$. From the results of these 2 molecules, it turns out that the affinity value is not too far away when

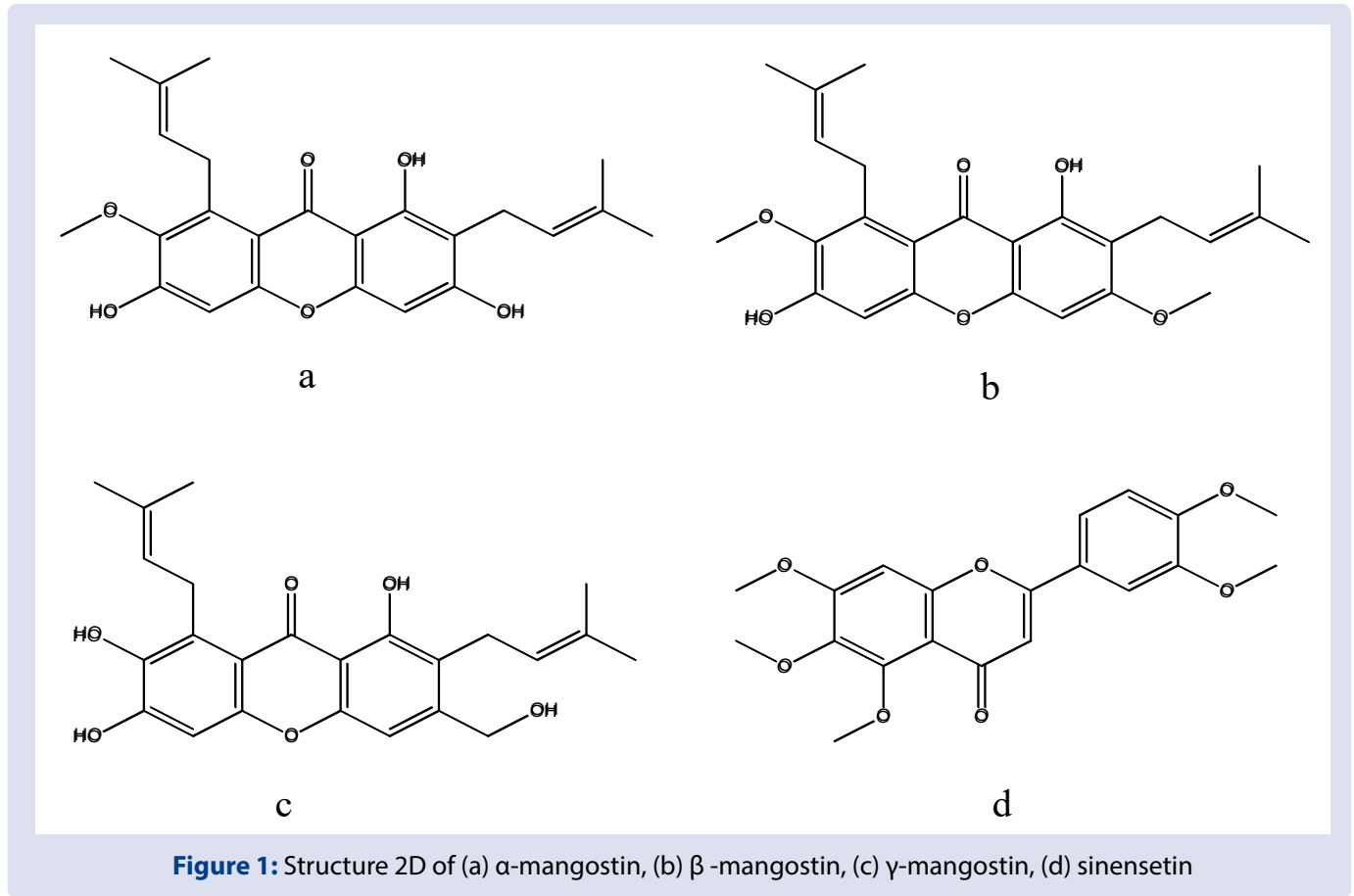




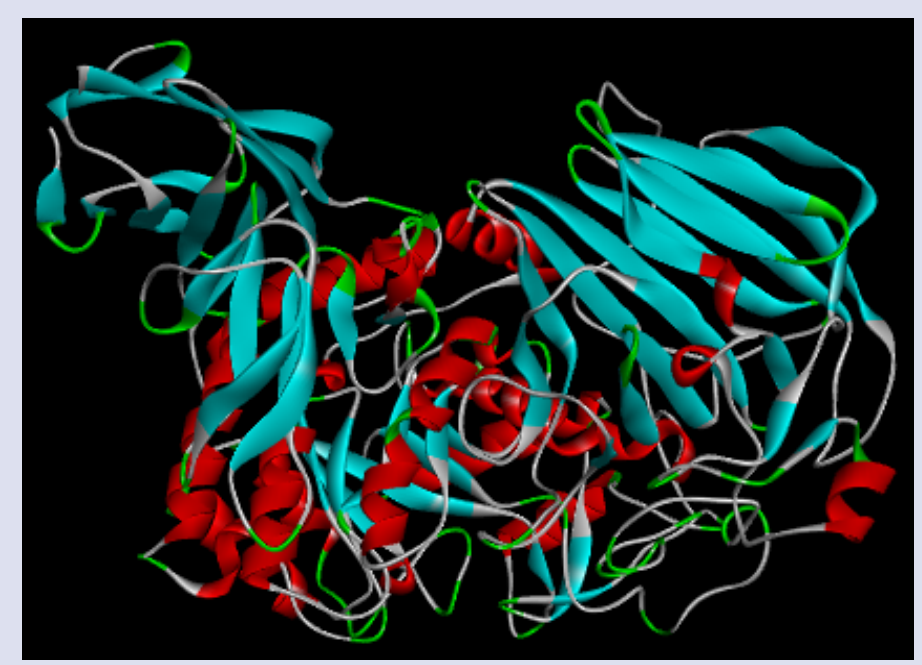

Figure 2: Macromolekul of Maltase-Glucoamylase.
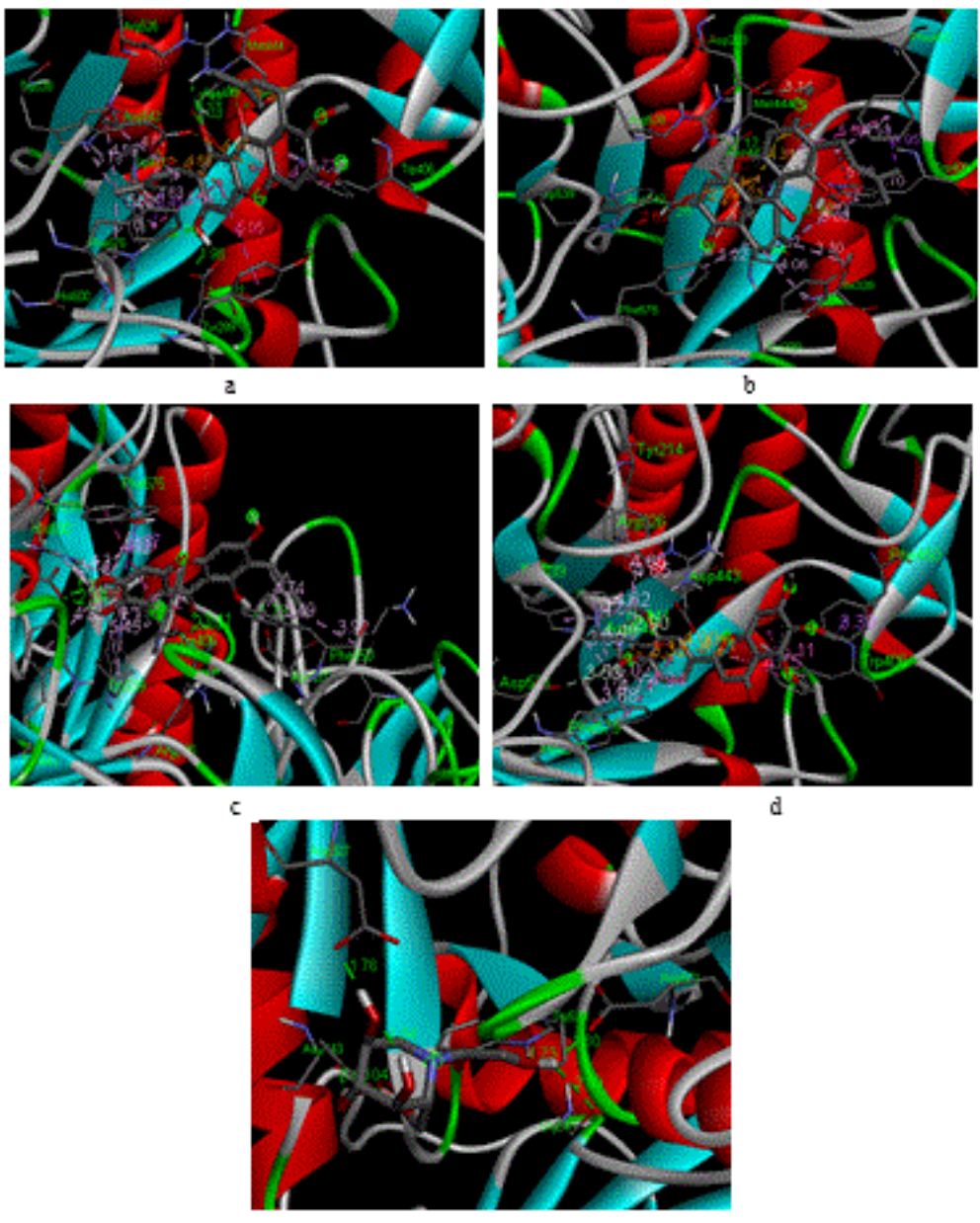

Figure 3: Binding patterns of compound (a) a-mangostin, (b) $\beta$-mangostin, (c) $\gamma$-mangostin, (d) sinensetin, (e) miglitol into the binding site of maltase-glucoamylase (PDB:3CTT). 
compared to miglitol, which is a positive control, which has a binding energy of $-9.14 \mathrm{kcal} / \mathrm{mol}$ and a constant inhibition of 1.99 , this can be seen from (Table 1).Hydrogen bonding also contributes to the affinity of the ligand to the protein/receptor due to the electrostatic interaction between the oxygen or nitrogen atom of the ligand and the hydrogen atom of the protein amino acid. The more hydrogen bonds and van der Waals bonds that are formed, the more stable the ligand bond with the protein. The same amino acid residues also show a higher probability of the test ligand having the same activity as the comparison ligand (Miller et al, 2015). Hydrogen bonds and van der Waals bonds along with amino acid residues can be seen in (Table 2). Alpha mangostin has 5 hydrogen bonds, with 2 amino acid residues that are the same as miglitol (Asp443 and Asp 327), $\beta$-mangostin has 2 hydrogen bonds, $\gamma$-mangostin has 3 hydrogen bonds with 1 amino acid residue which is the same as miglitol (Asp327), whereas sinensetin has 2 hydrogen bonds with 1 amino acid residue which is the same as miglitol (Asp 571).

ADMET predictions can be seen from (Table 3). Where the prediction of absorption is expressed by the value of intestinal absorption, the distribution is expressed by the value of VDss and BBB permeability, metabolism is expressed by CYP2D6 substrate and inhibitor, excretion is expressed by the value of total clearance, and toxicity is expressed by hepatotoxicity and $\mathrm{LD}_{50}$. It can be seen that the intestinal absorption (human) value of the tested compounds is around $89.40 \%-98.99 \%$, so it can be predicted that the four compounds will be absorbed very well in the human intestine. The VDss is a steady-state volume of distribution that predicts the value total dose of the drug would need to be uniformly distributed to give the same concentration as in blood plasma. The test compounds VDss are range from -0.55 to $0.01(\log \mathrm{L} / \mathrm{kg})$, the predicted results showed VDss relatively low (under $-0,15$ ). The BBB (Blood Brain Barrier) values of a-mangostin and sinensetin above -1 , which means that they can penetrate the $\mathrm{BBB}$ moderately. However, for $\beta$-mangostin and $\gamma$-mangostin, the BBB value was less than -1 indicating a poor distribution to the brain. In the table, it can be seen that none of the four compounds act as substrates or inhibitors of CYP2D6, so it can be predicted that all test compounds to be metabolized by the enzyme cytochrome P450. The total Clearance value of the test compounds ranges from 0.35 to 0.78 , and from these values it can be predicted the compound's excretion. From the results Table 4 of the hepatotoxicity prediction, none of the compounds that have no active compounds cause mutagenic effects and do not cause hepatotoxic effects. ${ }^{9}$ For more definite ADMET results from mangostin derivatives and sinensetin, it must be followed by testing in vitro and also in vivo.

\section{CONCLUSION}

The ADMET of mangostin derivatives $(\alpha, \beta$, and $\gamma$ ) and sinensetin can be predicted by the pkCSM online tool, and they showed good affinity on maltase-glucoamylase target compared to standard drugs like miglitol.

\section{ACKNOWLEDGEMENTS}

This research was suppoerted by Hibah Penelitian Konsorsium Riset Unggulan Perguruan Tinggi (KRUPT), RistekDikti, TA. 2020. The researcher also thanks to the supervisor who has helped in the research work.

Table 1: Molecular docking binding affinity of mangostin derivatives, sinensetin, miglitol showed by binding energy and inhibition constant.

\begin{tabular}{ccc|}
\hline Compound & Binding energy $(\mathrm{kcal} / \mathrm{mol})$ & Inhibition constant $(\mu \mathrm{M})$ \\
\hline$\alpha$-mangostin & $-7,84$ & 1,78 \\
$\beta$-mangostin & $-8,29$ & 832,54 \\
$\gamma$-mangostin & $-8,95$ & 273,09 \\
Sinensetin & $-7,45$ & 3,46 \\
Miglitol & $-9,14$ & 1,99 \\
\hline
\end{tabular}

Table 2: Ligands and amino acid residues interaction. Hydrogen bonds distance were given, van der walls interactions were indicated by tick $(\sqrt{ })$.

\begin{tabular}{ccccccccccccccc}
\hline Compound & Asp203 & Arg526 & Thr205 & Tyr214 & Asp443 & Phe450 & Met444 & lle328 & Asp327 & His600 & Asp542 & Asp571 & Tyr299 & Asp542 \\
a-mangostin & $\sqrt{ }$ & $2,32 \AA$ & $\sqrt{ }$ & - & $2,03 \AA$ & $\sqrt{ }$ & $3,56 \AA$ & $\sqrt{ }$ & $1,96 \AA$ & $2,78 \AA$ & - & $\sqrt{ }$ & - & - \\
$\beta$-mangostin & - & $2,17 \AA$ & - & - & - & - & - & - & $\sqrt{ }$ & $\sqrt{ }$ & $2,26 \AA$ & - & - & - \\
$\gamma$-mangostin & $1,73 \AA$ & $2,28 \AA$ & - & $\sqrt{ }$ & $\sqrt{ }$ & - & - & $\sqrt{ }$ & $2,34 \AA$ & - & $\sqrt{ }$ & $\sqrt{ }$ & - & $\sqrt{ }$ \\
Sinensetin & $\sqrt{ }$ & - & - & - & - & - & $\sqrt{ }$ & - & - & - & $2,90 \AA$ & $3,53 \AA$ & $\sqrt{ }$ & - \\
Miglitol & - & $\sqrt{ }$ & - & - & $2,04 \AA$ & - & $\sqrt{ }$ & $\sqrt{ }$ & $1,76 \AA$ & $\sqrt{ }$ & $\sqrt{ }$ & $1,80 \AA$ & $\sqrt{ }$ & $\sqrt{ }$
\end{tabular}

Table 3: Prediction ADMET of mangostin derivatives and sinensetin using the pkCSM online tool program.

\begin{tabular}{|c|c|c|c|c|c|c|c|c|}
\hline Molecule Name & $\begin{array}{l}\text { Intestinal } \\
\text { absorption } \\
\text { (human) }\end{array}$ & VDss (human) & $\begin{array}{c}\text { BBB } \\
\text { permeability }\end{array}$ & $\begin{array}{l}\text { CYP2D6 } \\
\text { substrate }\end{array}$ & $\begin{array}{l}\text { CYP2D6 } \\
\text { inhibitor }\end{array}$ & Total Clearance & Hepatotoxicity & $\mathrm{LD}_{50}(\mathrm{~mol} / \mathrm{kg})$ \\
\hline a-mangostin & 89,79 & $-0,23$ & $-1,12$ & No & No & 0,48 & No & 1,86 \\
\hline$\beta$-mangostin & 91,64 & $-0,32$ & $-0,26$ & No & No & 0,49 & No & 2,17 \\
\hline$\gamma$-mangostin & 89,40 & -0.55 & $-1,14$ & No & No & 0.35 & No & 1,34 \\
\hline sinensetin & 98,99 & 0,01 & $-0,99$ & No & No & 0,78 & No & 2,11 \\
\hline
\end{tabular}




\section{REFERENCES}

1. Cardona F, Parmeggiani C, Faggi E, Bonaccini C, Gratteri P, Sim $L$, et al. Total Syntheses of Casuarine and Its 6-O-a-Glucoside: Complementary Inhibition towards Glycoside Hydrolases of the GH31 and GH37 Families. Chemistry A European Journal. 2009;15:1627-36.

2. Husen SA, Winarni D, Salamun, Ansori ANM, Susilo RJK, Hayaza. Hepatoprotective Effect of Gamma-mangostin for Amelioration of Impaired Liver Structure and Function in Streptozotocin-induced Diabetic Mice. IOP Conf. Series: Earth and Environmental Science 217 (2019).

3. Ibrahim SRM, Mohamed GA, Khayat MT, Ahmed S, Haded HA, Alshali KZ. Mangostanaxanthone VIIII, A New Aanthone from Garcinia mangostana Pericarps, a-Amylase Inhibitory Activity, and Molecular Docking Studies. Brazilian Journal of Pharmacognosy. 2019;29:20612.

4. Lee D, Kim YM, Jung K, Chin YW, Kang KS. Alpha-Mangostin Improves Insulin Secretion and Protects INS-1 Cells from StreptozotocinInduced Damage. International Journal of Molecular Sciences 217. 2018;19.

5. Manurung K, Sulastri D, Zubir N, Ilyas S. In Silico Anticancer Activity and In Vitro Antioxidant of Flavonoids in Plectranthus amboinicus. Pharmacognosy Journal. 2021;12(6):1573-77.
6. Mohamed EAH, Siddiqui MJA, Ang LF, Sadikun A, Chan SH, Tan SC Asmawi MZ, Yam MF.Potent a-glucosidase and a-amylase inhibitory activities of standardized $50 \%$ ethanolic extracts and sinensetin from Orthosiphon stamineus Benth as anti-diabetic mechanism. BMC Complementary and Alternative Medicine. 2012;12:176.

7. Muchtaridi M, Dermawan D, Yusuf M. Molecular Docking, 3D Structure-Based Pharmacophore Modeling, and ADME Prediction of Alpha Mangostin and its Derivatives against Estrogen Receptor Alpha. Journal of Young Pharmacists. 2018;10(3):252-9.

8. Natesan S, Subramaniam R, Bergeron C, Balaz S. Binding Affinity Prediction for Ligands and Receptors Forming Tautomers and Ionization Species: Inhibition of Mitogen-activated Protein Kinaseactivated Protein Kinase 2 (MK2). Journal of Medicinal Chemistry. 2012;55(5):2035-47.

9. Pires DE, Blundell TL, Ascher DB. PkCSM: predicting small-molecule pharmacokinetic and toxicity properties using graph-based signatures. Journal of Medicinal Chemistry. 2015;58(9):4066-72.

10. Sumaryada T, Arwansyah, Roslia AW, Ambarsari L, Kartono A Molecular Docking Simulation of Mangostin Derivatives and Curcuminoid on Maltase-Glucoamylase Target for Searching Anti-diabetes Drug Candidates. 1ST International Conference on Biomedical Engineering (IBIOMED), Yogyakarta, Indonesia. 2016. 


\section{GRAPHICAL ABSTRACT}

Predict ADMET of $\alpha-\beta-, \gamma-$ mangostin ligand and sinensetin use pkC5M online tool

(http:/biogiz.unimelb.edu.auphesm/prediction) and BIOVIA Discover Studio 2020 for get the visualitation

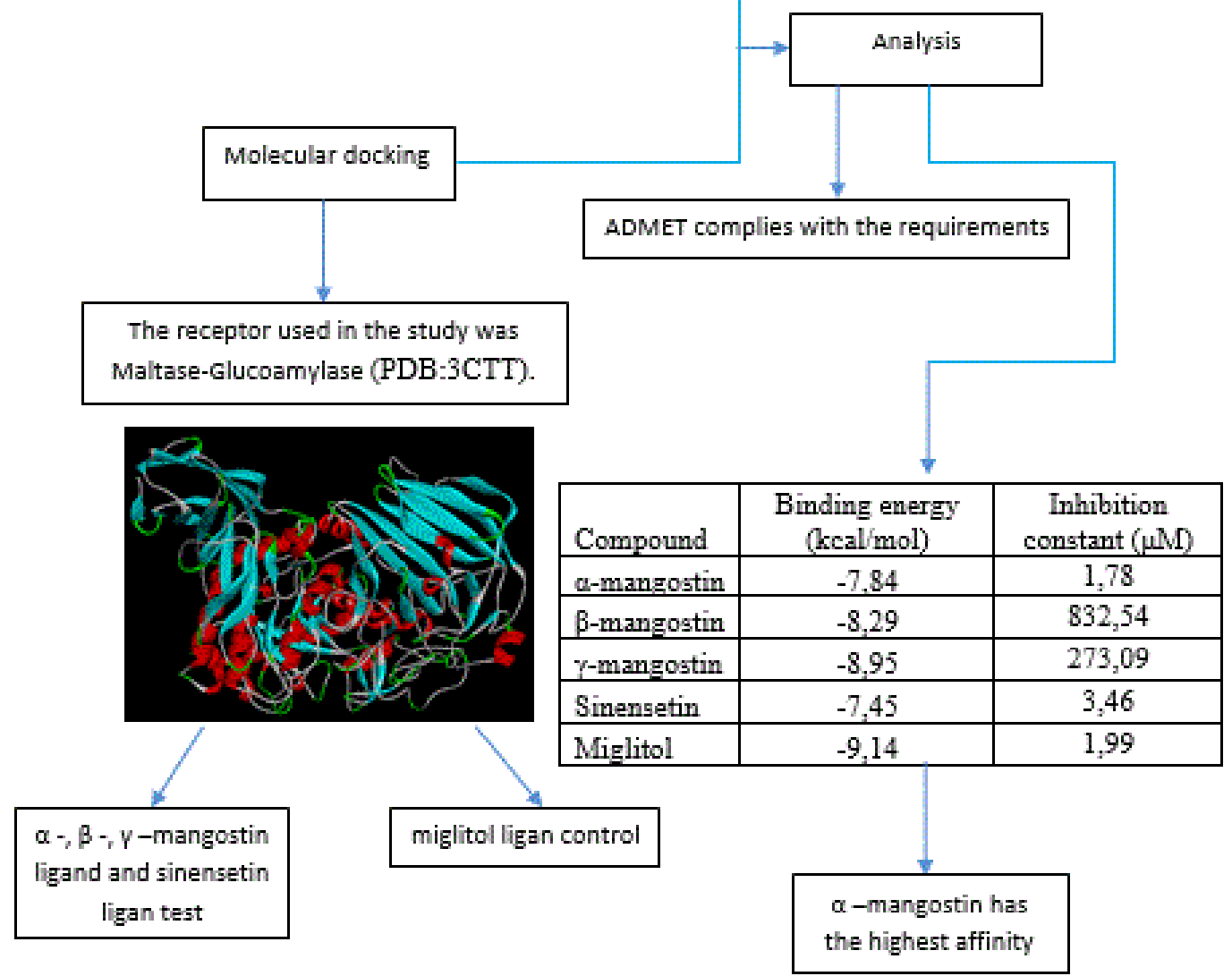

\section{ABOUT AUTHORS}

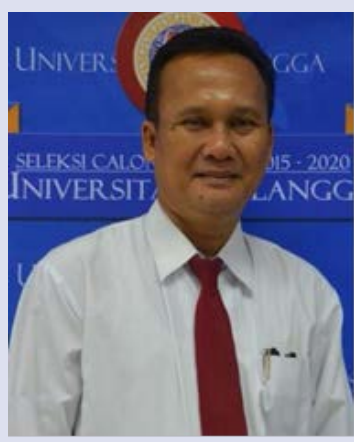

Sukardiman is a professor from the Department of Pharmaceutical Sciences at Airlangga University. He has a lot of research experience in the field of herbal plant activities as anticancer, antidiabetic, biochemical, toxicity and herbal medicine standardization. He is a member of the national commission for herbal medicine in Indonesia and has done many national and international publications. 

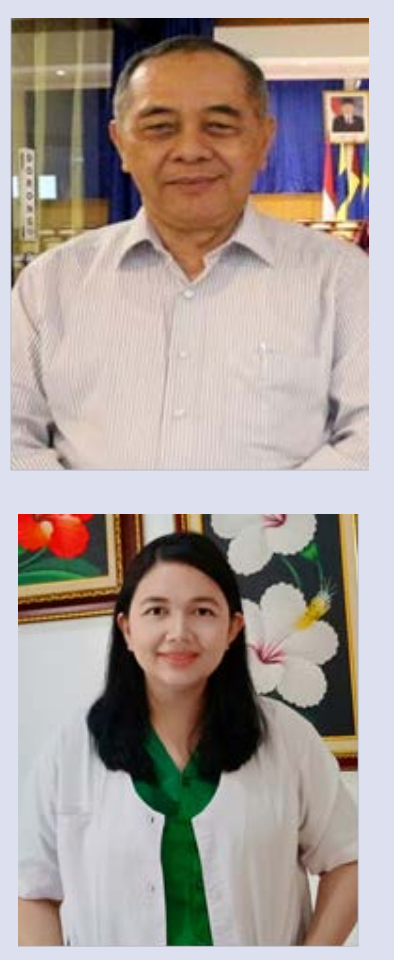

Suharjono is a professor from the Department of Practical Pharmacy at Airlangga University. He has research experience in the fields of pharmacology, drug therapy, pharmacokinetics and drug interactions. He has coached many undergraduate, master and doctoral students and has conducted national and international publications.

Intan is a master student at the Faculty of Pharmacy from Airlangga University. She has experience in standardizing mangosteen extract raw materials.

Cite this article: Prasetyanti IK, Sukardiman, Suharjono. ADMET Prediction and In silico Analysis of Mangostin Derivatives and Sinensetin on Maltase-Glucoamylase Target for Searching Anti-Diabetes Drug Candidates. Pharmacog J. 2021;13(4): 883-889. 